AJIT-e: Online Academic Journal of Information Technology

2014 Spring/Bahar - Cilt/Vol: 5 - Sayı/Num: 15

DOI: 10.5824/1309-1581.2014.2.003.x

http://www.ajit-e.org/?menu=pages\&p=details_of_article\&id=116

\title{
Ayrık Dalgacık Dönüşümü Bileşenlerine Ait İstatistiksel Veriler ile Epileptik EEG İşaretlerinin Sınıflandırılması
}

Tuğba PALABAŞ, istanbul Arel Üniversitesi, tugbapalabas@arel.edu.tr

ÖZET Beynin elektriksel aktivitesindeki anormal değişimden kaynaklanan epilepsi hastalığının teşhisinde EEG işaretlerinin analizi ve sınıflandırılması oldukça önemlidir. Bu çalışmada durağan olmayan EEG işaretlerinin spektral analizinde başarılı sonuçlar elde ettiği bilinen ayrık dalgacık dönüşümü kullamılarak dalgacık katsayılar elde edilmiştir. Bu katsayılara ait en kü̧̈ük değer, en büyük değer, standart sapma ve ortalamadan oluşan özellik vektörleri belirlenmiş ve model oluşturmadan sınıflandırma işlemi yaptığı için kısa sürede sonuç elde edebilen $k$ en yakın komşuluk ( $k N N$ ) algoritması ile de sınıflandırma işlemi gerçekleştirilmiştir. Yöntem 60 dakikalı $256 \mathrm{~Hz}$ örnekleme frekansına sahip nöbet ve nöbet dışı veriler ile test edilmiştir. Bu verilerin uzman doktor tarafindan işaretlenmiş segmentlerinden 110 saniyelik nöbet verisi ve 110 saniyelik nöbet dışı veri \%50 oranında örtüşme ile alınmış ve analiz için kullanılacak veri setleri oluşturulmuştur. İndirgenmiş vektörlerin $k N N$ algoritması ile sinıflandırılması sonucunda nöbet ve nöbet dışı verinin doğru sinıflandırma başarısı \% 83'e ulaşmışıtır.

Anahtar Kelimeler: EEG, Ayrık dalgacık dönüşümü, kNN

\section{Classification of Epileptic EEG Signals Using Statistical Data Belongs to the Discrete Wavelet Transform Components}

\footnotetext{
ABSTRACT Analysis and classification of EEG signals is very important in the diagnosis of seizure which result from abnormal turnover in brain electrical activity. In this study, discrete wavelet coefficients are obtained by using wavelet transform that is known to achieve successful results in spectral analysis of the non-stationary EEG signals. The feature vectors are determined consisting of minimum value, maximum value, mean and standard deviation belongs to these coefficients and classification is also performed with $\mathrm{kNN}$ algorithm which may obtain the result in a short time because of that a model isn't set for classification. The metod is tested with seizure and non-seizure data which are 60 minutes and have $256 \mathrm{~Hz}$ sampling frequency. The seizure data with and non-seizure data with 110 seconds are taken from the marked segments with $50 \%$ overlap of these data by specialist and data sets are formed to be used for analysis. As a result of the classification of the reduced vectors with $\mathrm{kNN}$ algorithm, the success of correct classification of the seizure and non-seizure data are $83 \%$.
}

Keywords: EEG, Discrete wavelet transform, $k N N$ 


\section{Giriş}

Epileptik nöbet; beynin normal aktivitesi dışında, ani elektrik yayılması sonucu ortaya çıkan nörolojik bir bozukluktur. Dünyada 100 kişiden 1'ini etkileyen bu hastalığın ilaçla ya da cerrahi olarak tedavisi mümkündür. Uygun epilepsi ilaçları ile hastaların \%70'i tedavi edilebilmektedir. Hastaların \%30'u dirençli epilepsi grubunda olduğundan yalnızca bir kısmının farklı cerrahi yöntemlerle tedavisi mümkündür. Epilepsi teşhisi konması için kişinin en az iki defa epileptik nöbet geçirmiş olması gerekmektedir. Epilepsi teşhisinde nörolojik müdahale ardından nörolojide rutin olarak kullanılan; kişinin beyin aktivitesindeki anormalliklerin tespit edilebildiği elektroensefalografi (Electroencephalogram-EEG)'dir. Farklı tetkikler ile birlikte EEG kayıtları uzmanlarca incelenerek epilepsi sendromunun türü belirlenmekte ve hasta için en uygun ilaç tedavisine karar verilebilmektedir. Ancak EEG verilerinin görsel olarak taranması vakit alıcıdır ve beyinde farklı durumlarda epileptik deşarjlara benzeyen dalga formlarının da meydana gelmesi hastalık tanısı konmasını zorlaştırmaktadır. Bu nedenle epilepsi tanısı konmasında doktorun işini kolaylaştırmak için verilerin bilgisayar ortamında analizini sağlayan çalışmalar yapılmış, farklı yöntemler önerilmiştir. [1]'de kayan pencere analizinden yararlanarak AKA yöntemi ile 12 hastanın toplam 49 nöbetine karşılık gelen EEG verilerine ait öznitelikler elde edilmiş, veriler $\mathrm{kNN}$, DVM ve KA yöntemleri ile 10 katlı çapraz doğrulama kullanılarak sinıflandırılmış, yöntemlere ait duyarlılık ve belirlilik oranları hesaplanmış, \%80 üzeri duyarlılık ve \%95 üzeri belirlilik elde edilmiştir. Bu sonuçlara dayalı olarak AKA yönteminin epileptik nöbet teşhisinde umut verici olduğu sonucuna varılmıştır. [2]'de ADD dönüşümü ile işaretlerin spektral çözümlemesinin ardından istenilen çözünürlükte elde edilen veriler karar ağaçları ve karar kuralları ile 10 katlı çapraz geçerlilik testi kullanılarak sinıflandırılmıştır. Karar ağaçları ile \%96,6 ve 99,70 aralığında başarı; karar kuralları ile \%95,3 ile \%98 aralığında başarı elde edilmiştir. Epileptik işaretlerin sınıflandırılmasında karar ağaçlarının daha başarılı olduğu sonucuna varılmıştır. [3]'de epileptik ve normal EEG işaretleri bir kişisel bilgisayara aktarılmıştır. Her bir hastadan kaydedilen EEG sinyaline, Hızlı Fourier Dönüşümü (HFD) uygulanmıştır. Hastaların HFD sonuçları sinirsel - bulanık sistem ile sınıflandırılmış ve \%90 doğru sınıflandırma başarısı elde edilmiştir. [4]'de gözleri açık sağlıklı gönüllülerden (Küme A), epilepsi öncesi (Küme D) ve epilepsi krizi esnasında (Küme E) epilepsi hastalarından elde edilen ham EEG verilerinden ADD ile istatistiksel özellikler çıkarılmış ve ELM ile sınıflandırma işlemi gerçekleştirilmiştir. Yöntem ile A-E veri kümesi için \%98-\%100, A-D veri kümesi için \%97-\%100 arasında değişen oranlarda sınıflandırma başarısı elde edilmiştir. [5]'te ilk olarak EEG sinyalleri ayrık dalgacık dönüşümü kullanılarak delta, teta, alfa, beta ve gama alt-bantlarına ayrıştırılmıştır. Adından her bir alt banttan istatistiksel özellikler çıkarılmış ve SVM kullanılarak EEG sinyalleri, epilepsi olup olmamasına göre sınıflandırılmıştır. [6]'da İlinti Boyutu, Dalgacık-entropisi ve Destek Vektör Makinesi (DVM) içeren kompozit bir sistem ile sağlıklı ve nöbet anındaki sinyallerin ayrıştırılması amaçlanmıştır. Dalgacık analizi ile elde edilen öznitelikler ile her bir EEG bölütü için öznitelik vektörü oluşturulmuş ve bu vektörlerin sınıflandırılması için DVM kullanılmıştır. Önerilen yöntem \%98 başarı ile sınıflandırma yapabilmiştir. [7]'de

EEG işaretlerinin sınıflandırılmasında farklı yöntemlerin farklı durumlar için performansları değerlendirilmiştir. 9 ayrı veri seti ile C4.5, knn ve svm algoritmaları incelenmiş, her durum için yöntemlerin doğruluk oranları ifade edilmiştir. Daha sonra yapılacak araştırmalar için 
yol gösterici özelliğe sahip bir çalışma sunulmuştur. [8]'de anestezi altındaki bir hastadan alınan EEG verileri incelenmiş; bant geçiren filtre, Fourier dönüşümü (FFT), dalgacık dönüşümü ve güç spektral yoğunluğu gibi farklı yöntemler uygulanarak elde edilen sonuçlara göre yeni yapılacak çalışmalara katkı sağlayacak önerilerde bulunulmuştur. [9]'da EEG işaretlerinin olasılık dağılımını kullanan çok katmanlı algılayıcı sinir ağı epilepsi teşhisi için önerilmiştir. EEG işaretlerinin alt bantlara ayrılmasında dalgacık dönüşümü kullanılmış ve her bir alt bandın katsayıları K-means algoritması ile kümelenmiştir. Dalgacık katsayılarının kümelere dağılımından hesaplanan olasılık sonuçları yapay sinir ağı girişine verilmiş ve \%98,40 oranında doğru sınıflandırma başarısı elde edilmiştir. [10]'da çok katmanlı algılayıcı yapay sinir ağı modeli kullanılarak EEG işaretlerinin sınıflandırılması amaçlanmıştır. EEG işaretleri, ayrıklaştırma işlemi ile yeniden düzenlenerek her bir segmente ayrık dalgacık dönüşümü uygulanmış ve dalgacık katsayıları elde edilmiştir. Yapay sinir ağı modeli ile sınıflandırma yapılmış ve sınıflandırma girişi olarak elde edilen katsayılara ait ortalama, standart sapma ve entropi değerleri kullanılmıştır. İki farklı deney yapılmış ve \%99,6 ile \%100 oranında doğrulukla sınıflandırma yapılmıştır.

Bu çalışmada da epileptik EEG işaretlerinin sınıflandırılması amaçlanmıştır. Nöbet ve nöbet dışı işaretlere ait öznitelik vektörlerinin belirlenmesinde ayrık dalgacık dönüşümü, verilerin sınıflandırılmasında da kNN algoritması kullanılmıştır. Oldukça kısa süre \%83 oranında doğru sınıflandırma başarısı elde edilmiştir.

\section{Materyal ve Metot}

Epileptik nöbet tahmini için önerilen yöntem 4 adımdan oluşmaktadır. Physionet veri tabanından alınan EEG sinyallerine ait .mat dosyalarından nöbet dışı ve epilepsi anına ait veri setleri oluşturulmuştur. Ardından sınıflandırmada kullanılacak özniteliklerin elde edilmesi için deneysel olarak başarısı değerlendirilerek daubechies-1 dalgacık ailesi kullanılmış, sadece 4 . seviyeden dalgacık katsayıları belirlenmiştir.

Bu adımları genel olarak ifade eden akış diyagramı Şekil 1'de gösterilmiştir.

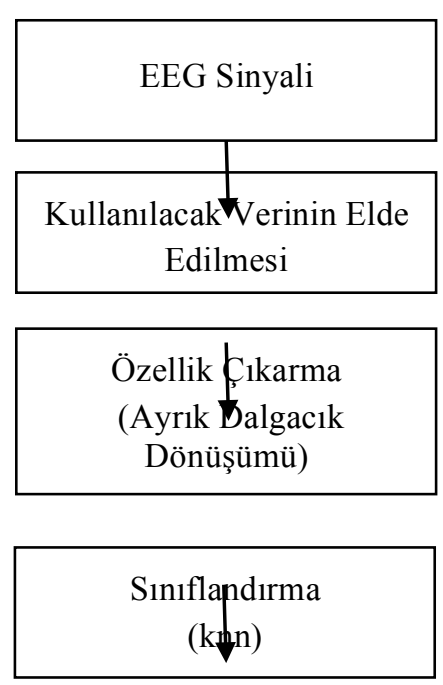

Şekil 1: Önerilen yönteme ait akış diyagramı 


\section{EEG Sinyali}

Bu çalışmada PhysioBank kayıtlarındaki CHB-MIT Scalp EEG Database (chbmit) verisinden yararlanılmıştır. Childeren's Hospital Boston'da elde edilen veriler, yaşları 3 ile 22 arasında değişen 5 erkek ve 1,5 ile 19 arasında değişen 17 kadın epilepsi hastasına aittir. Dirençli nöbeti olan ve anti-nöbet özellikli ilaçlar kullanan bu hastalar ilaçlar çekildikten sonra birkaç gün takip edilmiş, $256 \mathrm{~Hz}$ örnekleme frekansına EEG sinyalleri elde edilmiştir.

\section{Kullanılacak Verinin Elde Edilmesi}

Nöbet tahmini için EEG verisine ait özniteliklerin elde edilmesinde öncelikle 20sn uzunluklu pencereler oluşturulmuştur. Dirençli nöbet geçiren hastalara ait EEG verisinden 10'ar saniyelik kaydırma sonucu \%50 örtüşme ile elde edilen 20 saniyelik 10 segment belirlenmiştir. Uzman doktor tarafından belirlenmiş nöbet anına ait 10 segment ve nöbet olmadığ 1 ana ait 10 segment ile 3 hasta için eşit uzunluklu olarak elde edilen veri setleri özellik çıkarma işlemi ardından eğitim ve test için kullanılmıştır. Çalışmada kullanılan verilerin elde edildiği hastalara ait bilgiler Tablo 1'de gösterilmiştir.

Tablo 1: EEG verisi kullanılan hasta bilgileri

\begin{tabular}{|c|c|c|c|}
\hline Örnek & Dosya Adı & Cinsiyet & Yaş \\
\hline 1 & chb05 & $\mathrm{K}$ & 7 \\
\hline 2 & chb08 & $\mathrm{E}$ & 3.5 \\
\hline 3 & $\mathrm{chb} \mathrm{15}$ & $\mathrm{E}$ & 16 \\
\hline
\end{tabular}

\section{Ayrık Dalgacık Dönüșümü}

Epilepsi hastalarına ait durağan olmayan EEG işaretlerinin spektral analizi için yüksek frekanslarda küçük boyutlu, düşük frekanslarda büyük boyutlu pencere kullanarak en iyi zaman-frekans çözünürlüğü sağlamayı amaçlayan dalgacık dönüşümü ile özellik çıkarma işlemi gerçekleştirilmiştir. Bu dönüşümde Şekil 2' de gösterilen 4 . seviyeden dalgacık ağacı ve h(n), g(n) filtreleri için daubechies-4 filtresi kullanılmıştır. [13] 


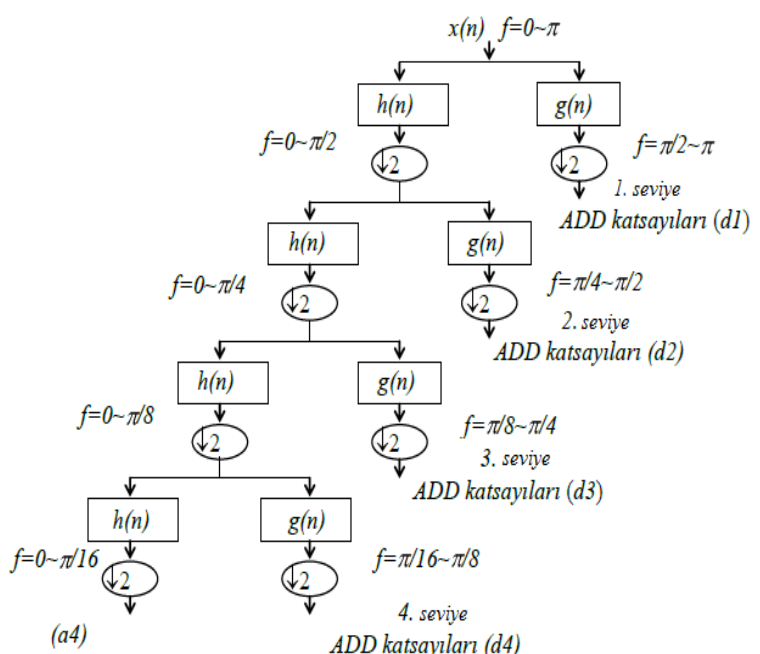

Şekil 2: 4. Seviyeden dalgacık ağacı [12]
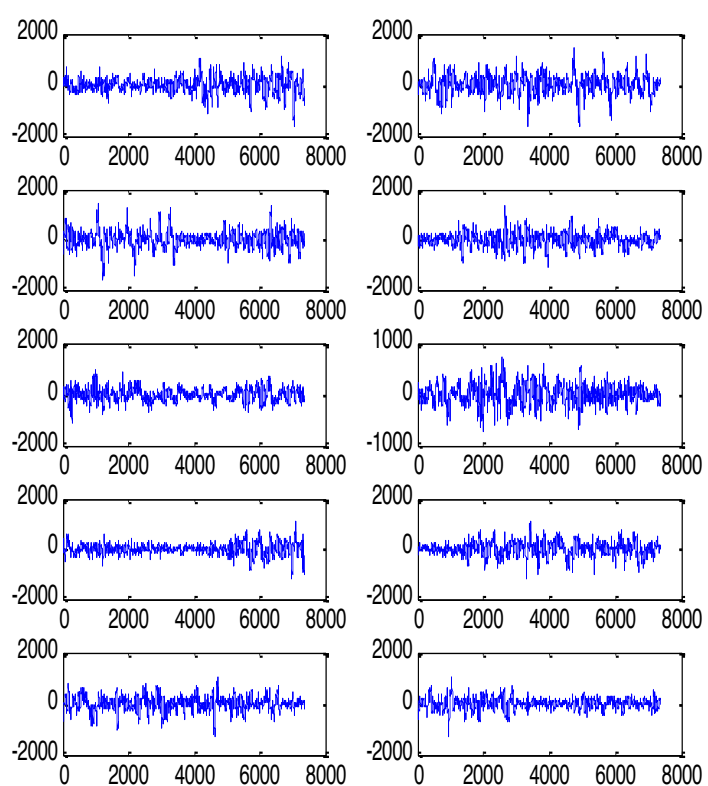

Şekil 3: Bir hastaya ait nöbet dışı EEG bölütlerinin ayrık dalgacık dönüşümü ile spektrum analizi 


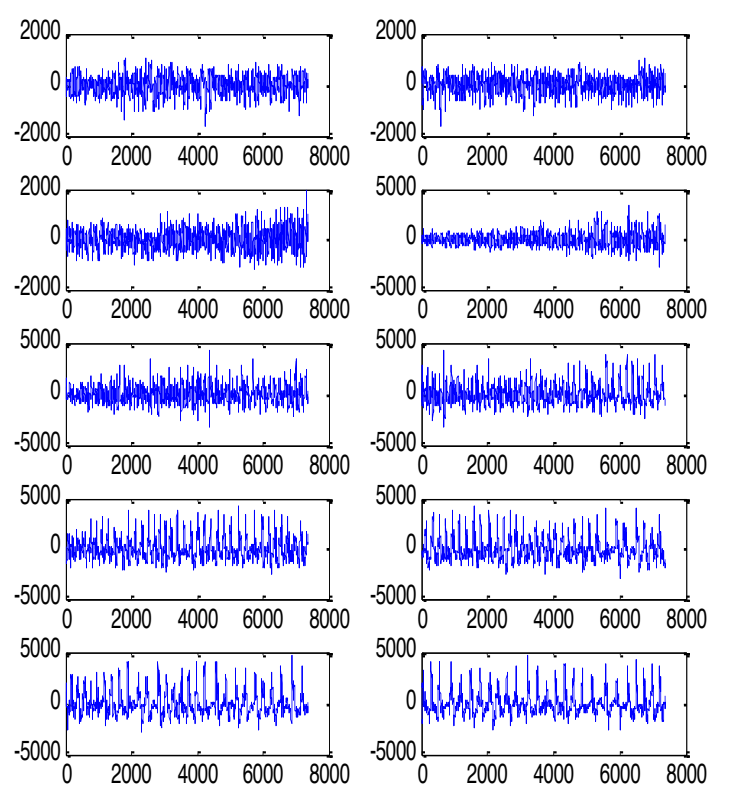

Şekil 4: Bir hastaya ait nöbet anındaki EEG bölütlerinin ayrık dalgacık dönüşümü ile spektrum analizi

Nöbet dışı EEG verisine ait frekans spektrumu Şekil 3'te, epileptik EEG verisine ait frekans spektrumu Şekil 4 'te gösterilmiştir. Epileptik sinyallerde uzun sivri uçların görsel olarak da yoğunluğu dikkat çekmektedir.

\section{Sinıflandırma}

Ayrık dalgacık dönüşümü ile elde edilen indirgenmiş vektörlere ait en küçük değer, en büyük değer, standart sapma ve ortalama değer hesaplanmıştır. Bu nitelikler ile nöbet anına ve nöbet dışı ana ait bilgiler içeren yeni özellik vektörü oluşturulmuştur. Özellik çıkarma işleminin ardından elde edilen yeni veri seti eğitim ve test için kullanılarak denetimli öğrenme yöntemlerinden biri olan kNN algoritması ile sinıflandırma işlemi gerçekleştirilmiştir.

kNN algoritmasına göre sınıfı belirlenmesi gereken yeni örneğin, eğitim setindeki tüm örnekler ile arasındaki mesafe, farklı hesaplama yöntemleri ile belirlenebilmekte ve bu örnekler içerisinden $\mathrm{k}$ tane en yakın mesafedeki örnek seçilmektedir. Yeni örnek, $\mathrm{k}$ tane örnek arasında en fazla örneği olan sınıfa atanmaktadır. Bu algoritmanın en önemli özelliği model oluşturulmamasıdır; bu sebeple hızlı sonuç alınmaktadır.

Bu çalışmada epilepsi hastalarına ait olan EEG sinyallerinden nöbetin olduğu ve olmadığ1 durumlar için yalnızca iki farklı sınıf verisinin sınıflandırılması amaçlandığından kNN algoritması kullanılarak sınıflandırma problemi çözülmüştür. Örnekler arasındaki uzaklıkların hesaplanmasında öklid bağıntısı kullanılmıştır ve $\mathrm{k}$ değeri 10 olarak belirlenmiştir. 
Şekil 5'te kNN algoritması kullanılarak yeni gelen kare örnek için en yakınındaki 10 örnek belirlenmiştir; kümelerden birinde 4 en yakın, diğerinde 6 en yakın örnek vardır. Algoritma kuralına göre yeni örnek 6 tane yakın mesafede örneğin olduğu kümeye atanmaktadır.

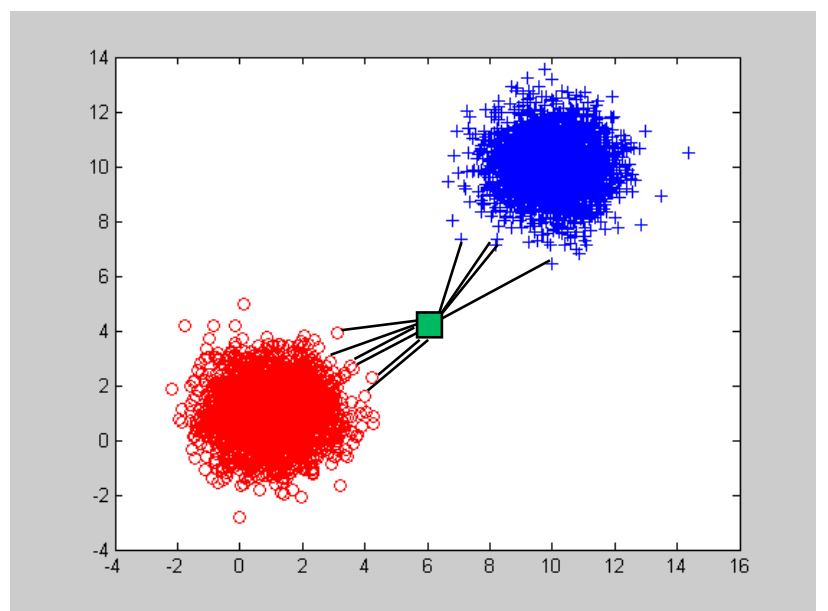

Şekil 5: kNN algoritması ile yeni örneğin sınıfının belirlenmesi

Dalgacık katsayılarına ait en küçük değer, en büyük değer, standart sapma ve ortalama değerini içeren giriş öznitelik vektörü olarak kullanıldığı kNN sınıflandırma algoritması ile EEG işaretleri \%83 doğrulukla kısa sürede sınıflandırılmıştır.

\section{Tartışma ve Sonuçlar}

256Hz örnekleme frekansına sahip 60 dakikalık nöbet ve nöbet dişı veri kullanılarak uzman doktor tarafından işaretlenmiş aralıklardan \%50 oranında örtüşme içeren 110 saniyelik nöbet ve nöbet dışı veri için yeni veri setleri elde edilmiştir. Elde edilen bu verilere ait öznitelik vektörlerinin belirlenmesi için durağan olmayan sinyallerdeki başarısından dolayı ayrık dalgacık dönüşümü kullanılmıştır. Ayrık dalgacık dönüşümünde deneysel olarak daha yüksek başarı sağladığından daubechies-4 filtresi kullanılmıştır ve yalnız 4 . seviye katsayıları elde edilmiştir. Dalgacık dönüşümü ile elde edilen öznitelik vektörleri kullanılarak sınıflandırma işlemi gerçekleştirilmiştir. KNN sınıflandırma algoritması ile kısa sürede nöbet ve nöbet dışı veriler için \%83 oranında doğru sınıflandırma başarısı elde edilmiştir.

Spektal analizde ayrık dalgacık dönüşümü ve sınıflandırmada kNN algoritması ile epilepsi teşhisinde hızlı ve etkin sayılabilecek sonuca ulaşıldığı görülmüştür.

Çalışmanın bir sonraki aşamasında örnek sayısı artırılıp farklı sınıflandırma teknikleri değerlendirilerek en yüksek sınıflandırma başarısının elde edilmesi amaçlanmaktadır. 


\section{References}

[1] Özdemir N., Duman F., Yıldırım E., "Ampirik Kip Ayrışımı Yoluyla Epileptik Nöbet Teşhisi", 2011 IEEE 19th Signal Processing and Communications Applications Conference (SIU 2011), s. 813-816, 20-22 Nisan 2011, Antalya.

[2] Kaya Y., Ertuğrul Ö. F., Tekin R., Epileptik EEG İşaretlerinin Sınıflandırılmasında Karar Kuralları ve Karar Ağaçlarının Kullanılması", Bilim ve Kültür Sempozyumu, 18-20 Nisan 2012, Batman.

[3] Barışçı N., Müldür S., "Epileptik EEG Sinyallerinin Sinirsel - Bulanık Sistem ile Sınıflandırılması", Politeknik Dergisi, Cilt: 6, Sayı: 2, s. 445-449, 2003.

[4] Kaya Y., Tekin R., “Epileptik Nöbetlerin Tespiti için Aşırı Öğrenme Makinesi Tabanlı Uzman Bir Sistem", Bilişim Teknolojileri Dergisi, Cilt: 5, Sayı: 2, Mayıs 2012.

[5] Kumari S. S., Jose J. P., "Seizure Detection In EEG Using Time Frequency Analysis and SVM", Emerging Trends in Electrical and Computer Technology (ICETECT), 2011, s. 626-630, 23-24 Mart 2011, Tamil Nadu.

[6] Bayram M., Acar H., "EEG Sınıflandırma Amaçlı Bir Kompozit Sistem”, Mühendislik Dergisi, Dicle Üniversitesi Mühendislik Fakültesi, cilt: 4, sayı: 1, s. 5-12, Nisan 2013.

[7] Sun S., Zhang C., Zhang D., "An experimental evaluation of ensemble methods for EEG signal classification", Pattern Recognition Letters, vol. 28, no. 15, p. 2157-2163, 1 Nov. 2007.

[8] Coşkun M., İstanbullu A., "EEG İsaretlerinin FFT ve Dalgacık Dönüşümü ile Analizi”, XIV. Akademik Bilişim Konferansı, 1-3 Şubat 2012, Uşak.

[9] Orhan U., Hekim M., Özer M., “Kümelemeye Dayalı Olasılık Dağılımı ve Yapay Sinir Ağı ile EEG İşaretlerinden Epilepsi Teşhisi", Akıllı Sistemlerde Yenilikler ve Uygulamaları Sempozyumu, s.1-4, 21-24 Haziran 2010, Kayseri.

[10] Orhan U., Hekim M., Özer M., “EEG İşaretlerinin Çok-Katmanlı Algılayıcı Yapay Sinir Ağı Modeli ile Sınıflandırılmasında Ayrıklaştırma Yaklaşımı", Biomedical Engineering Meeting (BIYOMUT), 2010, s. 1-4, 21-24 Nisan 2010, Antalya.

[11] Yılmaz Z., Bozkurt M. R., “Ayrık Dalgacık Dönüşümü Kullanarak Aritmilere Ait Özniteliklerin Çıkarılması", XIV. Akademik Bilişim Konferansı, 23-25 Ocak 2013, Antalya.

[12] Nizam A., "Karınca Koloni Optimizasyonuna Dayalı Yeni Bir Aritmi Sınıflama Tekniği", İstanbul Teknik Üniversitesi, Fen Bilimleri Enstitüsü, Doktora Tezi,2008. 